\title{
Oncolytic adenoviruses coated with MHC-I tumor epitopes for a new oncolytic vaccine platform
}

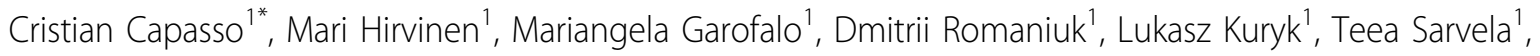
Andrea Vitale², Maxim Antopolsky', Aniket Magarkar ${ }^{1}$, Tapani Viitala', Teemu Suutari', Alex Bunker ${ }^{1}$, Marjo Yliperttula', Arto Urtti', Vincenzo Cerullo ${ }^{1}$

From 30th Annual Meeting and Associated Programs of the Society for Immunotherapy of Cancer (SITC 2015) National Harbor, MD, USA. 4-8 November 2015

\section{Background}

Oncolytic adenoviruses (OAds) demonstrated great potential for the treatment of cancer in many pre-clinical studies. The pre-existing immunity and their immunodominance, however, still limit the success of oncolytic virotherapy in cancer patients. Thus, a transition from

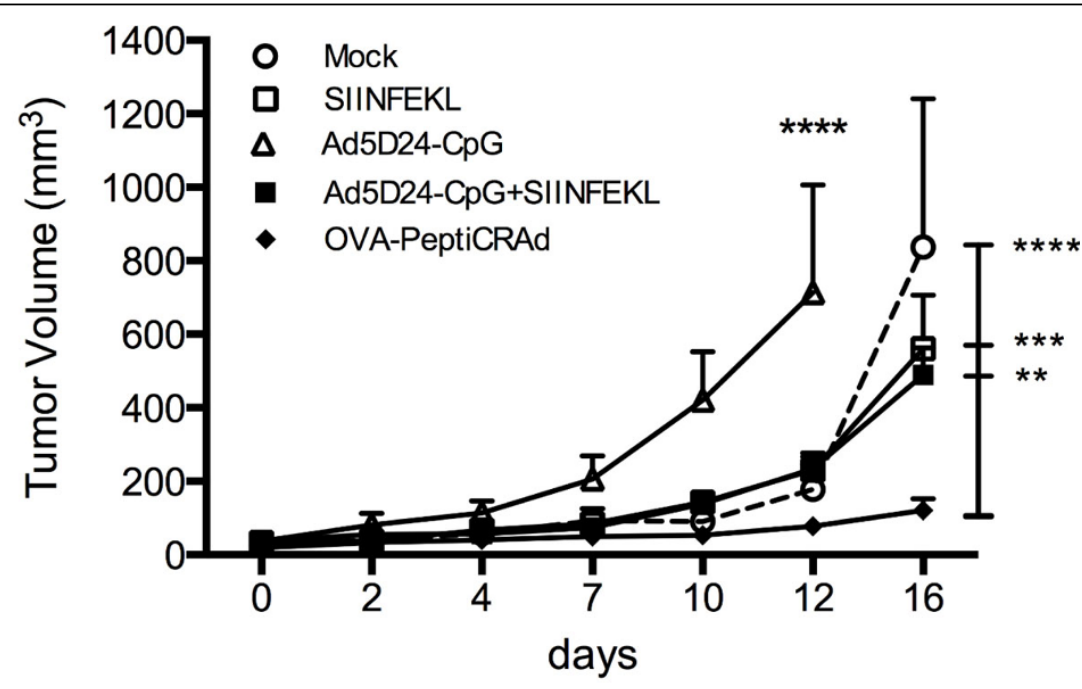

A

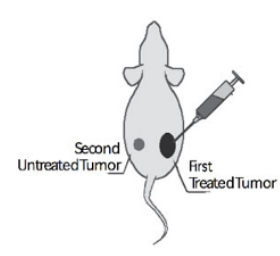

B

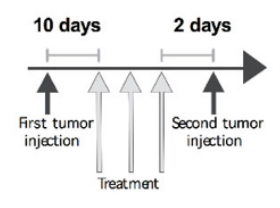

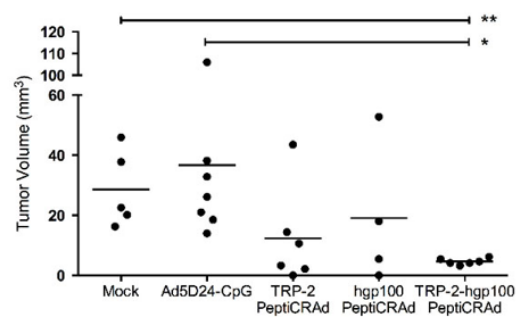

Figure 1

${ }^{1}$ University of Helsinki, Helsinki, Finland

Full list of author information is available at the end of the article 
oncolytic agents to oncolytic vaccines seems to be necessary, since the involment of the immune system may play a key role in the efficacy of OAds.

\section{Methods}

Therefore, we developed a new oncolytic vaccine platform that uses the virus as adjuvant for MHC-I tumor epitopes that are loaded onto the viral capsid via electrostatic interactions. By using the model epitope SIINFEKL, we studied the efficacy of the peptide-coated conditionally replicating adenoviruses (PeptiCRAds) in immunocompetent mice bearing B16-OVA melanomas.

\section{Results}

We found that OVA-targeting PeptiCRAds significantly reduced the tumor growth compared to controls (Figure 1) and elicited larger SIINFEKL-specific CD8 responses. Furthermore, we observed an increased presence of mature and epitope-specific dendritic cells in the spleens of mice treated with PeptiCRAd suggesting a modulating effect on antigen presenting cells. Next, we demonstrated that a PeptiCRAd targeting both TRP-2 and gp100 tumor antigens could elicit a broad immunological response able to significantly reduce the tumor growth of treated and, most importantly, untreated B16-F10 melanomas (Figure $2 \mathrm{~A}, \mathrm{~B}$ ). Finally, for the first time, immune deficient mice bearing human melanomas and engrafted with a human immune system were used to study the synergy between oncolytic activity and immunogenicity of oncolytic adenoviruses. A MAGE-A1-targeting PeptiCRAd, encoding for granulocyte-macrophage colony stimulating factor, was able to eradicate human melanomas and increased the percentage of human MAGE-A1-CD8 T cells compared to the naked OAd.

\section{Conclusions}

In conclusion, we demonstrated that the immunogenicity of OAds can be exploited to drive the immune response towards choosen epitopes and that this approach allows for rapid re-targeting without the need of genetic modifications, making PeptiCRAds a suitable platform for the next generation of highly personalized cancer vaccine immunotherapies.

\footnotetext{
Authors' details

${ }^{1}$ University of Helsinki, Helsinki, Finland. ${ }^{2}$ University of Naples Parthenope, Naples, Italy.

Published: 4 November 2015
}

doi:10.1186/2051-1426-3-S2-P333

Cite this article as: Capasso et al: Oncolytic adenoviruses coated with MHC-I tumor epitopes for a new oncolytic vaccine platform. Journal for ImmunoTherapy of Cancer 2015 3(Suppl 2):P333.

\section{Submit your next manuscript to BioMed Central} and take full advantage of:

- Convenient online submission

- Thorough peer review

- No space constraints or color figure charges

- Immediate publication on acceptance

- Inclusion in PubMed, CAS, Scopus and Google Scholar

- Research which is freely available for redistribution

Submit your manuscript at www.biomedcentral.com/submit 